\title{
Composition and properties of peanut and sunflower oil blends
}

\section{Valerii Babenko', Volodymyr Bakhmach ${ }^{1}$, Oksana Porociuk ${ }^{1}$ Iryna Levchuk ${ }^{2}$, Olga Golubets ${ }^{2}$, Sergii Shkaruba ${ }^{2}$}

\author{
1 - National University of Food Technologie, Kyiv, Ukraine \\ 2 - Ukrmetrteststandard, Kyiv, Ukraine
}

Keywords:

Peanuts

Sunflower

Oil

Blend

Stability

Article history:

Received 16.09.2017

Received in revised

form 20.11.2017

Accepted 29.09.2017

Corresponding

author:

Volodymyr Bakhmach

E-mail:

nota_b@i.ua

\section{Abstract}

Introduction. Investigation of the properties of refined deodorized peanut and sunflower oil blends has been carried out in order to influence the indexes of their antioxidant properties on the basis of acid and peroxide numbers.

Materials and methods. The vegetable oils parameters were determined: acid number by titrometric method, the peroxide number by the iodometric method, iodine number by the Weiss method. Fatty acid composition was studied by gas-liquid chromatography on a Hewlett Packard HP-6890 chromatograph using a HP-88 capillary column.

Results and discussion. The antioxidant properties of vegetable oils were depended on the fatty acid composition, the natural properties and the method of obtaining. Analysis of the fatty acid content of peanut oil shows that it contains, among others, about $60 \%$ oleic, $19 \%$ linoleic and $9 \%$ palmitic fatty acids. Composition and properties of blends are regulated by peanut and sunflower oil ratio. Acid number of refined sunflower oil have increased from 0.3 to $0.6 \mathrm{mgKOH} / \mathrm{g}$ during 7 months storage. Such growth indicates rapid oxidation. Increasing the content of peanut oil in the blends leads to an increase of antioxidant stability. The peroxide number of the blend of $30 \%$ and $70 \%$ was lower than sunflower oil by $25 \%$. The acid number increase of this blend is significantly slower compared with others. This result is due to the fact that the composition of blends is abounded by fraction of monounsaturated fatty acids of peanut oil, which contains up to $60 \%$ of fatty acids Omega- 9 family addition.

Conclusions. Peanut and sunflower refined deodorized oil blends samples have better antioxidant properties than sunflower oil it self. The best ratio is a blend of 30:70 peanut and sunflower oil.

DOI: $10.24263 / 2310-$

1008-2017-5-2-9 


\section{Introduction}

The consumption of vegetable oils increases annually in the world that is why the development of new oil and fat products of high quality is important.

The use of peanut oil is multifaceted [1]. The consumption of peanut oil is known both in food industry and in medicine and cosmetology.

Peanut oil after the composition has a significant amount of vitamins, especially group B. This oil contains numerous microelements such as polyphenols, phospholipids, and phytosterols.

Peanut oil [2] contains to $60 \%$ of monounsaturated oleic acid Omega-9, also to $30 \%$ of unsaturated fatty acids Omega - 6, which contributes to a significant strengthening of the immune system, improve the system of sexual rights, normalize hormonal balance and blood cholesterol levels.

In particular, peanut oil is rich in folic acid that plays an important role in the regeneration and growth of cells with antioxidants reduce free radicals. Thus, the processes of organism aging are slowed. In addition, regular consumption of peanut oil improves the process of removing toxins and speed up metabolism in the body, which is considered the most important feature of food product.

The refined peanut oil is mostly used in confectionary [3]. This foodstuff sufficiently often consume with a large vitamin component and vitamin-rich energy value. Peanut oil even at the insignificant food consumption adds a feeling of satiety for a long time. Consumer properties of this oil are revealed when it is used for filling various salads and cold vegetable dishes. For deep-frying cooking consumption of peanut butter is two times lower than when using other oils. Peanut oil does not smoke.

The chemical composition and other characteristics of peanut oil is similar to olive, known for unique curative properties. However, the price of peanut oil significantly lower. Compared with the degree of saturation sunflower oil fatty acid peanut oil higher. In comparing to sunflower-seed oil, the degree of saturation of fat acids of peanut oil is higher. In Ukraine sunflower oil is the most widely used in mayonnaise recipes.

It is possible to assume that the development of technology blends with refined deodorized peanut and sunflower oils will allow taking advantage of the peanut butter along with the attractive price of sunflower oil and getting better quality characteristics of new oil fatty products [4].

\section{Materials and methods}

Blend of refined deodorized peanut and sunflower oils were prepared by mixing in the appropriate ratio of refined deodorized peanut oil of Swiss production and refined deodorized sunflower oil of Ukrainian origin.

Fatty acid composition of refined deodorized peanut oil compared with unrefined peanut oil was checked and obtained by its pressing from peanut kernels beans on laboratory screw press [5] and refined deodorized sunflower oil.

Fatty acid composition of oils was studied by gas-liquid chromatography on a Hewlett Packard HP-6890 chromatograph using a HP-88 capillary column [6].

Sensory properties of oils were evaluated for original appearance, color and smell of tasting technique $[6,8]$.

Determination of the acid number was performed according to the titration methodologies. 
Determination of the peroxide number was conducted according to iodometric methodologies.

\section{Results and discussion}

Comparative analysis of the fatty acid composition of refined deodorized and unpurified peanut oil, and sunflower oil is in Table 1.

Comparative description of fatty acid composition of vegetative oil

Table 1

\begin{tabular}{|l|c|c|c|}
\hline \multicolumn{1}{|c|}{ Fat acid } & Sample 1 & Sample 2 & Sample 3 \\
\hline Myristic & - & - & - \\
\hline Palmitic & 9,1 & 9,2 & 7,1 \\
\hline Palmetelaidic & 0,1 & 0,1 & 0,1 \\
\hline Stearin & 3,3 & 3,5 & 3,4 \\
\hline Oleic & 61,2 & 62,4 & 25,0 \\
\hline Linoleic & 19,2 & 17,6 & 62,9 \\
\hline Arachic & 1,5 & 1,4 & 0,2 \\
\hline Eicosanoid & 1,2 & 1,4 & - \\
\hline Gadoleic & - & - & \\
\hline Behenic & 2,6 & 2,4 & 0,7 \\
\hline Eicosatetraenoic & - & - & - \\
\hline Erucic & - & - & - \\
\hline Lignoretic & 1,4 & 1,5 & 0,13 \\
\hline Eicosapentaenoic & - & - & - \\
\hline Nervonic & - & - & - \\
\hline Docosahexaenoic & - & - & - \\
\hline Total & $\mathbf{1 0 0 , 0}$ & $\mathbf{1 0 0 , 0}$ & $\mathbf{1 0 0 , 0}$ \\
\hline
\end{tabular}

Sample 1 - Press unrefined peanut oil got in laboratory terms,

Sample 2 - Refined deodorized peanut oil (Erdnussöl) (Switzerland)

Sample 3 - Refined deodorized sunflower oil (Ukraine) 
Comparative sensory evaluation of the quality of oils

\begin{tabular}{|c|c|c|c|}
\hline Name of quality indexes, description & Estimation & $\begin{array}{c}\text { Sample } \\
1\end{array}$ & $\begin{array}{c}\text { Sample } \\
2\end{array}$ \\
\hline \multicolumn{4}{|c|}{ Taste and smell } \\
\hline $\begin{array}{l}\text { With the poorly expressed aftertaste of feedstock. } \\
\text { Tastes and smells are not allowed }\end{array}$ & 10 & 9 & 10 \\
\hline $\begin{array}{l}\text { With a strong taste of raw materials. Tastes and } \\
\text { smells are not allowed. }\end{array}$ & 10 & - & - \\
\hline \multicolumn{4}{|c|}{ Transparency } \\
\hline Transparent & 10 & 10 & 10 \\
\hline Transparent, allowed a slight turbidity & 10 & - & - \\
\hline \multicolumn{4}{|l|}{ Color } \\
\hline According to normative documents & 10 & 10 & 10 \\
\hline
\end{tabular}

Sample 1 - Refined deodorized peanut oil (Erdnussöl) (Switzerland), Sample 2 - Refined deodorized sunflower oil (Ukraine)

Analysis of fatty acid composition of peanut and sunflower oils shows that peanut oil has a very high ratio $\omega 3: \omega 6$ polyunsaturated fatty acids, which shows its high biological value. Peanut oil is balanced for fatty acid composition and is more intense than sunflower oil.

Refined deodorized peanut is oil of Swiss production is similar in fatty acid composition of peanut press unrefined oil received in the laboratory condition. Feature of peanut oil is also high in oleic acid, which provides a high antioxidant stability of sunflower oil blends.

Comparative Sensory evaluation of the quality of refined deodorized peanut and unflower oils is in Table. 2.

Refined deodorized peanut and sunflower oils were investigated with physical and chemical indexes (Table 3)

\section{Comparative description of physical and chemical indexes of refined deodorized peanut and sunflower oils}

Table 3

\begin{tabular}{|l|c|c|c|c|}
\hline \multicolumn{1}{|c|}{ Indexes } & Norm & Sample 1 & Sample 2 & Sample 3 \\
\hline $\begin{array}{l}\text { Acid value, } \\
\text { mg KOH/g no more }\end{array}$ & 0,5 & 0,38 & 0,25 & 0,37 \\
\hline $\begin{array}{l}\text { Peroxide number } \\
1 / 2 \text { mmol / kg, no more }\end{array}$ & 10 & 1,2 & 2,0 & 1,1 \\
\hline $\begin{array}{l}\text { Iodic number, } \\
\text { g J2/100g, no more }\end{array}$ & $83-105$ & 94 & $125-145$ & 136 \\
\hline
\end{tabular}

Sample 1 - Refined deodorized peanut oil (Erdnussöl) (Switzerland),

Sample 2 -Refined deodorized sunflower oil,

Sample 3 - Refined deodorized sunflower oil (Ukraine) 
According to the research of sensory characteristics, we can conclude that refined deodorized peanut oil satisfies the requirements. And according to data presented in Table 3 , it is shown that refined deodorized peanut oil of Swiss production for its physical and chemical rates do not exceed the norms and for those indexes it is like a refined deodorized sunflower oil of Ukrainian origin.

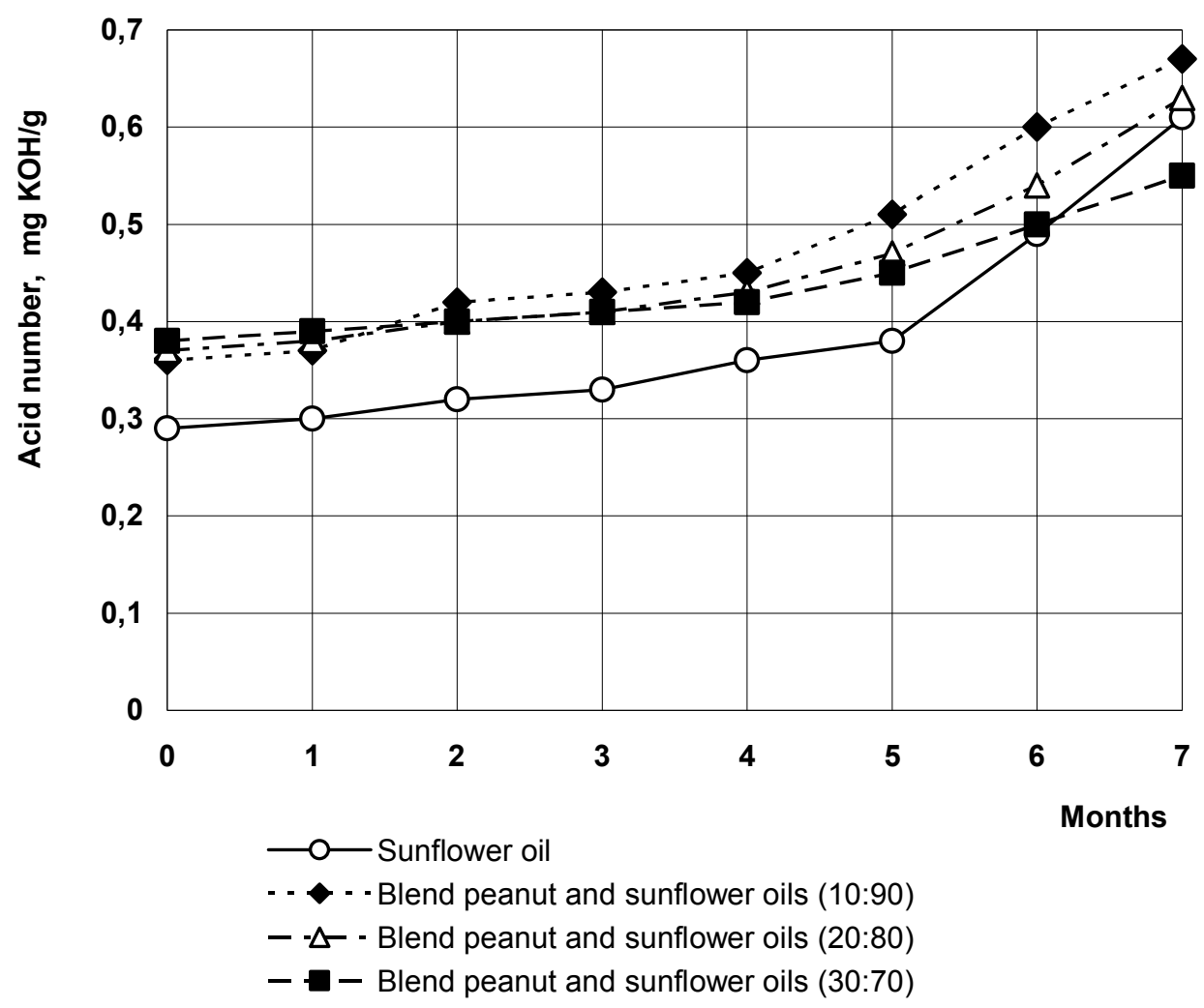

Figure 1. The change in acid number blend peanut and sunflower oils during 7 months' storage

On this basis, it was proposed to use peanut refined deodorized oil for developing blends of the given oil with refined deodorized sunflower oil.

Blends from peanut and sunflower oils were worked out at correlation according to 10:90, 20:80, 30:70, as a norm does not provide blends recipes with peanut oil. For this purpose the recommended correlations of oils to olive or rape oil blends with sunflower oil. A study of changes of acid and peroxide numbers blends refined deodorized peanut and sunflower oil at the ratio of 10:90 respectively, 20:80, 30:70 under the influence of atmospheric oxygen during the blends storage at room temperature compared with sunflower oil. Curves changes in these indicators are presented in Figure 1 and Figure 2. 
According to our data, we can conclude that the change of acid and peroxide numbers in 7 months' storage the developed blends of peanut and sunflower oils does not exceed the norm and change similarly with acid and peroxide numbers of sunflower oil. Developed blends can be used in the formulations of other food products (the rational ratio peanut and sunflower oils is 30:70) [6].

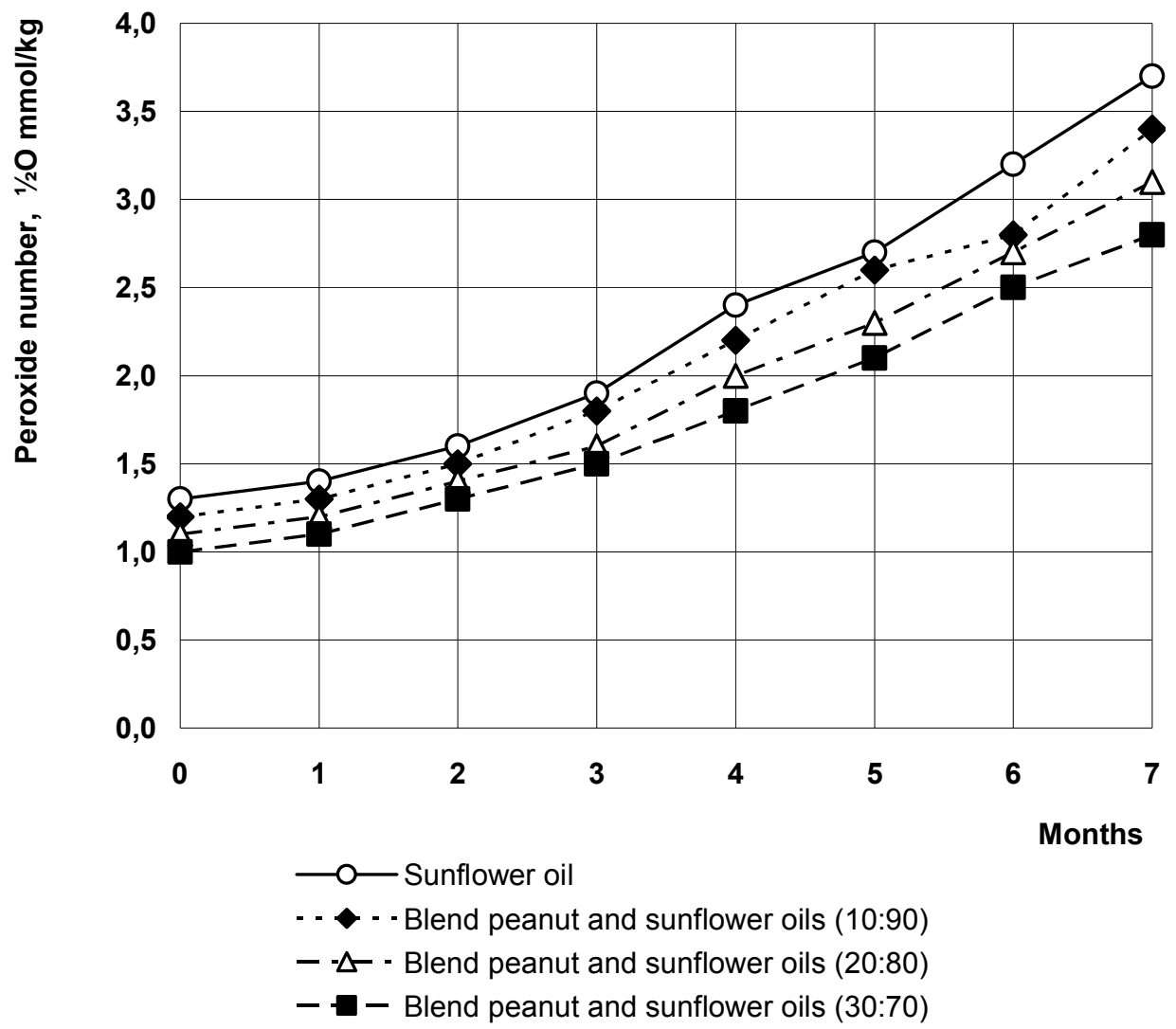

Figure 2. The change in the number of peroxide blend peanut and sunflower oils during 7 months' storage

\section{Conclusion}

Use of method of the mathematical planning of experiment in this work the optimal compounding of peanut and sunflower blends refined deodorized oils were developed. Our studies showed that the blend peanut and sunflower oils have high biological value as a new type of oil and fat products [7]. Developed blends of peanut and sunflower oil recipes can be used for food production [8-10]. 


\section{References}

1. Xiaoyan Zhao, Jun Chen, Fangling Du (2012), Potential use of peanut by-products in food processing: a review, Journal of Food Science and Technology, 49(5), pp. 521529

2. Brian David Craft, Agnieszka Kosińska, Ryszard Amarowicz, Ronald Bruce Pegg (2010), Antioxidant Properties of Extracts Obtained from Raw, Dry-roasted, and Oilroasted US Peanuts of Commercial Importance, Plant Foods for Human Nutrition, 65(3), pp. 311-318.

3. David C. Bean, Laurie S. Post (2014), Chocolate and Confectionary, The Microbiological Safety of Low Water Activity Foods and Spices, pp. 269-293.

4. Murali T. Variath, P. Janila (2017), Economic and Academic Importance of Peanut, The Peanut Genome, pp. 7-26.

5. Hooman Chodar Moghadas, Karamatollah Rezaei (2017), Laboratory-Scale Optimization of Roasting Conditions Followed by Aqueous Extraction of Oil from Wild Almond, Journal of the American Oil Chemists' Society, 94(6), pp 867-876.

6. Marilynn Schnepf, Gwen Spencer Jon Carlort (1991), Chemical and sensory characteristics of stored menhaden oil/soybean oil blends, Journal of the American Oil Chemists Society, 68(5), pp. 281-284

7. Babenko V., Bakhmach V. (2010), The technology of mayonnaise production, Products \& Ingredients, 4(87), pp. 36-37

8. Bakhmach V., Peshuk L. (2015), Improvement technology mayonnaise using vegetable raw materials, Food Industry, 18, pp. 27-31

9. Merve Yildirim, Gulum Sumnu (2016), Rheology, particle-size distribution, and stability of low-fat mayonnaise produced via double emulsions, Food Science and Biotechnology, 25(6), pp 1613-1618

10. Bakhmach V., Nosenko T., Berezka T. (2015), Improvement of technology of lowcalorie mayonnaise, Visnik of the National Technical University of KhPI, 44, pp. 1922. 